\title{
Estimating Cocaine Consumption in the Brazilian Federal District (FD) by Sewage Analysis
}

\author{
Adriano O. Maldaner, ${ }^{*, a}$ Luciana L. Schmidt, ${ }^{a}$ Marco A. F. Locatelli, ${ }^{b}$ Wilson F. Jardim, ${ }^{b}$ \\ Fernando F. Sodré, ${ }^{c}$ Fernanda V. Almeida, ${ }^{c}$ Carlos Eduardo B. Pereira ${ }^{d}$ and Cristiano M. Silva ${ }^{d}$ \\ ${ }^{a}$ Departamento de Polícia Federal, Instituto Nacional de Criminalística, \\ SAIS Quadra 07 Lote 23, 70610-200 Brasília-DF, Brazil \\ ${ }^{b}$ Instituto de Química, Universidade de Campinas, CP 6154, 13083-970 Campinas-SP, Brazil \\ 'Instituto de Química, Universidade de Brasília, CP 4478, 70904-970 Brasília-DF, Brazil \\ ${ }^{d}$ Companhia de Saneamento Ambiental do Distrito Federal, 71928-720 Águas Claras-DF, Brazil
}

Este é o primeiro trabalho que relata a ocorrência de resíduos de cocaína (COC) e benzoilecgonina $(\mathrm{BE})$ em amostras coletadas em seis estações de esgoto diferentes (ETE) instaladas no Distrito Federal (DF) do Brasil. As concentrações de BE nos afluentes de esgoto foram utilizadas para calcular o consumo de cocaína ( $\mathrm{kg}^{2} \mathrm{no}^{-1}$ por 1000 habitantes) em cada uma das regiões atendidas pelas ETE, em duas campanhas de amostragem (março e junho de 2010). Dentre as ETE estudadas, amostras provenientes de Samambaia apresentaram as maiores concentrações (de 3866 a $2477 \mathrm{ng} \mathrm{L}^{-1}$ de BE e 805 a $579 \mathrm{ng} \mathrm{L}^{-1}$ de COC) e doses por habitante (mais de 13 doses habitante ${ }^{-1}$ por ano). A extrapolação para toda a população do DF indica um consumo anual alcançando 1,0 tonelada de cocaína base livre, ou 1,1 tonelada de cloridrato de cocaína. Este trabalho também aborda a influência da forma de apresentação da cocaína (base livre ou sal cloridrato) e a integração com resultados de perfil químico na busca de estimativas mais realistas, principalmente no que se refere aos pontos de vista da criminalística e da segurança pública.

This is the first report on the occurrence of cocaine (COC) and benzoylecgonine (BE) residues in six samples collected from different wastewater treatment plants (WTP) located in the Brazilian Federal District (FD). Concentrations of BE in the influent sewage were used to calculate cocaine consumption ( $\mathrm{kg}$ year $^{-1}$ per 1000 inhabitants) for each region attended by the WTP from two sampling campaigns (March and June, 2010). Among the WTP studied, samples from Samambaia showed higher concentrations (from 3866 to $2477 \mathrm{ng} \mathrm{L}^{-1}$ of BE and 805 to $579 \mathrm{ng} \mathrm{L}^{-1}$ of COC) and doses per inhabitants (more than 13 doses inhabitant ${ }^{-1}$ per year). The extrapolation to the whole FD population points out to an annual consumption reaching 1.0 ton of free base cocaine, or 1.1 tons of cocaine hydrochloride. The work also addresses the influence of the cocaine presentation form (free base or hydrochloride) and the integration with chemical profiling results in a more realistic estimate, mainly concerning the viewpoints of forensics and law enforcement.

Keywords: cocaine, benzoylecgonine, sewage, estimate

\section{Introduction}

Estimating the amount of illicit drugs used by a certain population is one of the main challenges to forensic scientists working with law enforcement. The indicators normally used to follow up and evaluate the results of the police efforts, such as the news concerning the 20 tons of

*e-mail: adriano.aom@dpf.gov.br cocaine seized by the Brazilian Federal Police in 2008, ${ }^{1}$ are usually "out of perspective" and not reliable to estimate the total amount of drugs that really reaches the illicit market. Even in very expressive seizures it is difficult to evaluate the real impact of the apprehension on illicit traffic or drug consumption.

A biased estimation of the quantity of illicit drugs used by a population, indication of "hot spots" of the geographical distribution of the most used illicit drugs, 
such as cocaine, cannabis, LSD and amphetamine-type stimulants (ATS), can be used to guide law enforcement operations and public policies. In Brazil, obtaining realistic drug consumption indicators is not only critical, but imperative to subsidize the allocation of finite resources to obtain the best results from both health and public education initiatives.

The geographical proximity of Brazil to cocaineproducing countries (as a result of thousands of miles of borders), and the high and growing internal crack cocaine consumption, ${ }^{1}$ already considered epidemic throughout the country, has led the federal government to implement an integrated plan aiming to combat trafficking and drug consumption, as well as to invest in health treatment programs for people addicted to cocaine and other illicit drugs. ${ }^{2}$

In Brazil, the development of the PeQui project, a chemical profiling program based on detailed and systematic quantification of cocaine and regularly used adulterants (e.g. caffeine, lidocaine, etc.), as well as the typical coca alkaloids (e.g. cis/trans-cinnamoylcocaine) and residual solvents, is already bringing relevant information to the Federal Police related to cocaine seizures carried out on the Brazilian territory. ${ }^{3-6}$ The PeQui database has been built and used to reveal connections, based on statistical evaluation, between distinct seizures to help police investigations on controlled chemicals used to produce, dilute or adulterate cocaine.

An alternative to the epidemiological tools that have been used to give the official picture for occurrence and prevalence of illicit drugs in several countries, obtained by the integration of quantities seized by police, population surveys and health services records ${ }^{1,7-9}$ is the utilization of sewage to measure concentrations of illicit drugs and their metabolites. The methodological approach, named sewage epidemiology, was implemented in Italy in $2005^{10}$ and used by several groups in countries like Ireland, ${ }^{11}$ Spain,,${ }^{12,13}$ Belgium, ${ }^{14}$ USA, ${ }^{15}$ United Kingdom ${ }^{16}$ and France. ${ }^{17}$

The approach is based on the use of sampled urban sewage, composed by a pool of human metabolic excretion products (some of them resulting from illicit drug consumption), to quantify parent compounds or metabolites and thus back-calculate the amount used by the population served by that sewage system. The main advantages of this approach is to provide objective, quantitative, and near real-time profiles of illicit drug consumption as well as to estimate and compare consumption patterns (e.g. g day $^{-1}$, doses day ${ }^{-1}$, g day ${ }^{-1}$ per 1000 inhabitants or doses day $^{-1}$ per 1000 inhabitants). Sewage epidemiology has been applied worldwide to investigate the consumption of various drugs, especially cocaine and was recently reviewed by Van Nuijs et al. ${ }^{18}$ On the other hand, according to
Ort and co-workers, ${ }^{19}$ sampling techniques demand special attention to obtain reliable data from this source.

It is important to stress that besides the relative simplicity of the approach and the obvious utility of the results to the forensic field, there are some important issues that need to be considered, aiming to increase its reliability. Therefore, variations in forms of utilization (oral, injected, smoked), metabolic patterns, chemical stabilities and degradation, partitioning and sorption in the sewage matrix, and the sewer system specificities (size, flow rate, temperatures) have to be evaluated. Additionally, the sampling strategy used needs to be seriously considered in terms to validate the conclusions, as recently reviewed by Ort and co-workers. ${ }^{19}$

Concerning the high organic content in sewage, filtration and solid-phase extraction (SPE) pre-concentrations are generally used to reach the ng $\mathrm{L}^{-1}$ range of target analytes prior to analysis by liquid chromatography coupled to tandem mass spectrometry (LC-MS/MS). Several alternative SPE procedures and identification methodologies are reported in the literature, where the use of the SPE sorbents Oasis HLB or MCX, followed by LC separation carried out on reversed-phase columns, ionization by electrospray (ESI) and mass spectrometry performed on triple quadrupole equipment, operated in the multiple reaction monitoring (MRM) mode are the most frequently used approach. ${ }^{18}$

The aim of this work was, firstly, to evaluate the occurrence of cocaine and its main metabolite, benzoylecgonine, in raw sewage collected from selected wastewater treatment plants in the Brazilian Federal District using SPE-ESILC-MS/MS and, secondly, to evaluate the data obtained in terms of a forensic and law enforcement point of view, in order to generate empirical results that can contribute to an understanding of the illicit drugs consumption scenario in Brazil.

\section{Experimental}

\section{Chemicals}

Cocaine (COC) and benzoylecgonine (BE) standards (1 $\mathrm{mg} \mathrm{mL}^{-1}$ in methanol) were purchased from Cerilliant (Austin, TX, USA) and stored at $-20{ }^{\circ} \mathrm{C}$ in the dark. Working solutions containing both compounds were prepared by dilution of stock solutions with water:methanol, 90:10 (v/v). All working solutions and sample extracts were prepared with $0.1 \%$ LC-MS-grade formic acid (Fluka, Buchs, Switzerland) prior to analysis in order to improve analytical sensitivity. These solutions were prepared weekly and stored at $4{ }^{\circ} \mathrm{C}$, protected from light. 
Methanol (HPLC grade) was obtained from J. T. Baker (Xalostoc, Mexico). Hydrochloric acid ( $\mathrm{HCl}, 37 \%)$ was provided by Mallinckrodt (Paris, KT, USA). Purified water $(18.2 \mathrm{M} \Omega \mathrm{cm})$ was prepared in a Milli-Q Plus purification system (Millipore, MA, USA). Nitrogen for drying (99.995\% of purity) was supplied from liquid nitrogen (White Martins, Brazil).

\section{Background}

The analytical procedure to measure $\mathrm{COC}$ and BE was optimized by INCTAA (National Institute of Advanced Analytical Science and Technology) researchers through a collaborative program involving the Forensic Chemistry Service of the National Institute of Criminalistics of the Brazilian Federal Police (SEPLAB/ INC) and the environmental chemistry laboratories at the Universities of Brasilia (UnB) and Campinas (Unicamp), with collaboration of the Federal District Company of Environmental Sanitation (CAESB).

\section{Sampling}

This work was carried out in the Brazilian Federal District (FD). Brasilia, the capital, as well as several satellite cities constitutes the FD, a federative unit comparable to a state. Along with the nearest satellite cities, the FD has a population of about 2.6 million inhabitants. ${ }^{20,21}$ This region was appropriate to our study due to the relatively high percentage (>93\%) of wastewater collection and treatment. The vast majority of raw sewage produced in the FD is treated in 17 wastewater treatment plants (WTP). In this work, raw sewage samples were collected from six selected WTP, namely Melchior, Asa-Sul, Samambaia, Asa-Norte, Paranoá, and Riacho-Fundo, serving an equivalent population of approximately 1.5 million inhabitants. Figure S1 (see Supplementary Information) shows the FD in the Brazilian territory as well as the localization of the WTP studied in this work and the area covered by each WTP.
Raw sewage influents from the six investigated WTP were collected in March and June 2010. Two $12 \mathrm{~h}$-composite samples were collected from each WTP using a refrigerated automatic water/wastewater sampler (Teledyne Isco, Lincoln, NE), that uses a peristaltic pump to draw water through a sample tube, and the aliquots are then deposited into a collection bottle. Samples named as D (day) were collected between 7 AM and 7 PM whereas samples named as $\mathrm{N}$ (night) were obtained from $7 \mathrm{PM}$ to $7 \mathrm{AM}$. Composite samples were stored in dark glass bottles at $4{ }^{\circ} \mathrm{C}$ for a maximum of three days before further analytical steps. Table 1 shows the population covered by the six investigated WTP and the influent flow rate measured during the sampling period. As also shown in Table 1, the June 2010 sampling campaign included two additional WTP (Samambaia and Melchior) when compared to the March 2010 campaign.

\section{Sample preparation}

In the laboratory, raw sewage samples were filtered using $1.2 \mu \mathrm{m}$ pore-size glass microfiber filters (Schleicher \& Schuell, Dassel, Germany) and then passed through $0.45 \mu \mathrm{m}$ pore-size cellulose acetate membranes (Sartorius, Geottingen, Germany). Filtered samples $(0.2 \mathrm{~L})$ were transferred to pre-cleaned amber glass bottles and the $\mathrm{pH}$ was adjusted to 2.0 with a dilute $\mathrm{HCl}$ solution. Solidphase extraction of $\mathrm{COC}$ and $\mathrm{BE}$ was carried out using commercial cartridges containing $500 \mathrm{mg}$ of a hydrophilic/ lipophilic balanced $\mathrm{N}$-vinylpyrrolidone/divinylbenzene copolymer sorbent (HLB Oasis, Waters, Milford, USA). To avoid cross contamination, sample bottles and SPE cartridges were set up in series in a lab-made extraction system described elsewhere. ${ }^{22}$ The HLB cartridges were conditioned before use with $6 \mathrm{~mL}$ of methanol, $6 \mathrm{~mL}$ of purified water, and $6 \mathrm{~mL}$ of an $\mathrm{HCl}$ solution at $\mathrm{pH} 2.0$.

After the conditioning step, samples were passed through the cartridges at a flow rate of $5 \mathrm{~mL} \mathrm{~min}^{-1}$. The solid sorbent was then dried under a constant stream of $\mathrm{N}_{2}$ for

Table 1. Characteristics of the wastewater treatment plants investigated in this work

\begin{tabular}{|c|c|c|c|c|}
\hline \multirow{2}{*}{ WTP } & \multirow{2}{*}{ Cities/regions in FD covered by WTP } & \multirow{2}{*}{$\begin{array}{l}\text { Thousands of } \\
\text { inhabitants served }^{\mathrm{a}}\end{array}$} & \multicolumn{2}{|c|}{ Flow rate $/\left(\mathrm{L} \mathrm{s}^{-1}\right)$} \\
\hline & & & March $16^{\text {th }} / 17^{\text {th }}$ & June $1^{\text {st }} / 2^{\text {nd }}$ \\
\hline Melchior & Ceilândia, Taguatinga & 641.9 & $n s^{\mathrm{b}}$ & 768 \\
\hline Asa-Sul & $\begin{array}{l}\text { Asa Sul, Lago Sul, Guará, Núcleo Bandeirantes, Candagolândia, Águas } \\
\text { Claras, Cruzeiro }\end{array}$ & 522.8 & 1063 & 1549 \\
\hline Samambaia & Samambaia & 188.2 & $\mathrm{Ns}^{\mathrm{b}}$ & 1016 \\
\hline Asa-Norte & Asa Norte, Lago Norte & 117.3 & 491 & 648 \\
\hline Paranoá & Paranoá, Itapoã & 71.4 & 56 & 106 \\
\hline Riacho-Fundo & Riacho Fundo I & 68.6 & 52 & 44 \\
\hline
\end{tabular}

${ }^{\mathrm{a} F e d e r a l ~ D i s t r i c t ~ G o v e r n m e n t ~ d a t a ; ~}{ }^{20 \mathrm{~b}}$ not sampled. 
$20 \mathrm{~min}$. Analytes were recovered with $6 \mathrm{~mL}$ of methanol into previously cleaned glass tubes. This elution step was performed under vacuum using a 12-port Prep Sep manifold (Fisher Scientific, Fair Lawn, USA). The eluates were carefully evaporated to dryness with a gentle flow of $\mathrm{N}_{2}$ and the analytes were diluted to a final volume of $1.0 \mathrm{~mL}$ in a $0.1 \%$ formic acid solution in water:methanol, $90: 10(\mathrm{v} / \mathrm{v})$.

\section{$\mathrm{COC}$ and $\mathrm{BE}$ determination}

Diluted sample extracts were analyzed using an Agilent 1200 liquid chromatographic system, equipped with a microvacuum degasser, a binary pump, an autosampler, and a thermostatted column compartment, coupled to an Agilent 6410 triple quadrupole mass spectrometer equipped with an electrospray source (Agilent Technologies, Palo Alto, USA).

A Zorbax SB-C18 column $(30 \mathrm{~mm} \times 2.1 \mathrm{~mm}$ i.d., $3.5 \mu \mathrm{m}$ particle size, Agilent Technologies) was used for the chromatographic separation. Formic acid solutions $(0.1 \% \mathrm{v} / \mathrm{v})$ prepared in purified water and in methanol were used as mobile phase solvents at a flow rate of $0.3 \mathrm{~mL} \mathrm{~min}^{-1}$. The initial gradient condition, i.e., water:methanol, 90:10 (v/v), was maintained for 4 min followed by an increase of the relative methanol concentration from $10 \%$ to $100 \%$ in $6 \mathrm{~min}$. This composition was held for $5 \mathrm{~min}$. After readjusting to the initial conditions, the system was re-equilibrated for $7 \mathrm{~min}$. The temperature in the column compartment was kept in $35^{\circ} \mathrm{C}$ for 10 min followed by an increase to $45^{\circ} \mathrm{C}$ at $10^{\circ} \mathrm{C} \mathrm{min}^{-1}$. This temperature was held until the end of each chromatographic run. The injection volume varied between 5.0 to $10.0 \mu \mathrm{L}$.

After the chromatographic separation, analytes were ionized using the ESI source operating in the positive mode. Nitrogen was the drying gas at $350{ }^{\circ} \mathrm{C}$ with a flow rate of $10 \mathrm{~L} \mathrm{~min}^{-1}$. The nebulizer pressure was $55 \mathrm{psi}$ and the capillary voltage was set at $2500 \mathrm{~V}$.

Mass spectrometric analyses were carried out in the multiple reaction monitoring mode measuring the fragmentation products of the protonated molecular ions $[\mathrm{M}+\mathrm{H}]^{+}$for COC and BE, i.e., $\mathrm{m} / z 304.2$ and $\mathrm{m} / \mathrm{z}$ 290.2, respectively. Fragmentation was carried out in the collision cell using nitrogen as collision gas and appropriate collision-induced energies in order to produce adequate product ions. Each compound was quantified by MRM using the three most abundant precursor $\rightarrow$ product ion transitions as shown in Table 2.

Both drugs were quantified by external calibration using, at least, six-point analytical curves. Recovery tests were carried out in ultrapure water using $50 \mathrm{ng} \mathrm{L}^{-1}$ of each compound, river water $\left(200 \mathrm{ng} \mathrm{L}^{-1}\right)$ and raw sewage samples (2000 $\mathrm{ng} \mathrm{L}^{-1}$ ). Recovery percentages for both compounds in all tested samples varied between 95 and $105 \%$.

\section{Results and Discussion}

Concentrations of benzoylecgonine (BE) and cocaine (COC) measured in the WTP influents are shown in Table 3. Generally, it is possible to observe that concentrations of $\mathrm{BE}$ are higher than those obtained for $\mathrm{COC}$ in both sampling campaigns, as well as, for all WTP investigated. BE levels varied from 663 to $9719 \mathrm{ng} \mathrm{L}^{-1}$ whereas COC varied between 222 and $3690 \mathrm{ng} \mathrm{L}^{-1}$.

Based on the aforementioned results, an estimate of cocaine consumption was carried out considering the approach suggested by Zuccato et al. ${ }^{10}$ The basic idea considers that the concentration of benzoylecgonine (BE) in water $\left(\mathrm{ng} \mathrm{L}^{-1}\right)$ from sewage samples has to be multiplied by 2.33 to directly correlate with free base cocaine consumed. This approach takes into account the free based COC/BE molar mass ratio (1.048) and the average molar fraction (45\%) of a cocaine dose that is excreted as BE, according to different studies. For cocaine hydrochloride, the BE concentration has to be multiplied by 2.61 , because the molecular ratio $\mathrm{COC} . \mathrm{HCl} / \mathrm{BE}$ is 1.175 . Considering the flow rate of the WTP (Table 1) and the sampling period, it is possible to estimate the quantity of cocaine $\left(\mathrm{g} \mathrm{day}^{-1}\right)$ used by the population served by the sewage network at each sampling site.

Table 4 shows the estimated quantity of cocaine (free base and hydrochloride) consumed annually in the FD considering the data from both sampling campaigns. The results revealed good correlation between the estimated values in March and June, mainly in Paranoá WTP.

Table 2. Retention time and multiple reaction monitoring conditions for $\mathrm{COC}$ and $\mathrm{BE}$

\begin{tabular}{lcccc}
\hline Compound & Retention time / min & Fragmentor / V & Reaction transitions / $(\mathrm{m} / z)$ & Collision energy / V \\
\hline BE & 7.9 & 110 & $290.2 \rightarrow 168.2$ & 15 \\
& & & $290.2 \rightarrow 105.1$ & 30 \\
COC & & $290.2 \rightarrow 77.2$ & 35 \\
& \multirow{2}{*}{8.6} & 120 & $304.2 \rightarrow 182.2$ & 15 \\
& & & $304.2 \rightarrow 105.1$ & 30 \\
\hline
\end{tabular}


Table 3. Concentration of BE and COC in WTP influents samples in the Federal District, March 2010 and June 2010 samplings

\begin{tabular}{lcccc}
\hline \multirow{2}{*}{ Sample (WTP/ D or N $\left.{ }^{\mathrm{a}}\right)$} & \multicolumn{2}{c}{ March $2010 /\left(\mathrm{ng} \mathrm{L}^{-1}\right)$} & \multicolumn{2}{c}{ June $2010 /\left(\mathrm{ng} \mathrm{L}^{-1}\right)$} \\
\cline { 2 - 5 } & $\mathrm{BE}$ & $\mathrm{COC}$ & $\mathrm{BE}$ & $\mathrm{COC}$ \\
\hline Melchior/D & - & - & 3753 & 553 \\
Melchior/N & - & - & 3251 & 601 \\
Asa-Sul/D & 742 & 392 & 1330 & 174 \\
Asa-Sul/N & 675 & 410 & 3866 & 282 \\
Samambaia/D & - & - & 2477 & 805 \\
Samambaia/N & - & - & 1293 & 579 \\
Asa-Norte/D & 771 & 536 & 1761 & 298 \\
Asa-Norte/N & 663 & 646 & 4513 & 382 \\
Paranoá/D & 9717 & 3690 & 4625 & 645 \\
Paranoá/N & 2432 & 1921 & 4282 & 617 \\
Riacho-Fundo/D & 1915 & 222 & 4796 & 752 \\
Riacho-Fundo/N & 1288 & 705 & 966 \\
\hline
\end{tabular}

${ }^{a} \mathrm{D}$ (day) and $\mathrm{N}$ (night) composite samples.

Table 4. Estimated cocaine (free base and hydrochloride) consumed in the Federal District, March 2010 and June 2010 sampling campaigns

\begin{tabular}{lcccc}
\hline \multirow{2}{*}{ WTP } & \multicolumn{2}{c}{ March $2010 /\left(\mathrm{kg} \mathrm{year}^{-1}\right)$} & \multicolumn{2}{c}{ June $2010 /\left(\mathrm{kg}\right.$ year $\left.^{-1}\right)$} \\
\cline { 2 - 5 } Melchior & Free base cocaine & Cocaine hydrochloride & Free base cocaine & Cocaine hydrochloride \\
Asa-Sul & - & - & 199 & 223 \\
Samambaia & 56 & 63 & 152 & 170 \\
Asa-Norte & - & - & 256 & 287 \\
Paranoá & 26 & 29 & 72 & 80 \\
Riacho-Fundo & 30 & 34 & 36 & 40 \\
\hline
\end{tabular}

However, the discussion in this work will be focused only on the June campaign due to the higher number of inhabitants covered by the six WTP investigated in this campaign, i.e., $72 \%$ of the total FD population. Based on the data displayed in Table 4, it was possible to calculate a total free base cocaine consumption of 0.73 ton for the population covered by the six investigated WTP. The extrapolation for the whole FD population pointed to an annual consumption of cocaine reaching 1.0 ton of free base cocaine and/or 1.1 tons of cocaine hydrochloride.

The influence of the cocaine presentation form (free base or hydrochloride) has been considered an important issue to be discussed, mainly concerning the law enforcement point of view. The molar mass difference, $12 \%$ higher in cocaine hydrochloride, becomes more significant if the estimate reaches the values observed in this work.

Table 5 shows the annually estimate for consumed cocaine in the FD per 1000 inhabitants, considering each WTP sampled and $0.1 \mathrm{~g}$ of free base cocaine per dose. Both absolute quantities (Table 4) and doses per inhabitants (Table 5) results for Samambaia WTP presented the highest levels of cocaine consumption, reaching more than 13 doses per inhabitant per year. The Paranoá and Asa-Norte WTP also showed relatively high consumption (4980 and 6112 doses year ${ }^{-1}$ per 1000 inhab., respectively), especially when compared to Asa-Sul, Melchior and Riacho-Fundo WTP (2908 to 3095 doses year-1 per 1000 inhab.).

One should also bear in mind that the data of sewage epidemiology provides results for pure cocaine $(100 \%$ purity), while samples seized in international drug traffic or those sold on the streets, rarely shows more than $90 \%$ purity. Indeed, the initial results of the PeQui project show average

Table 5. Estimated free base cocaine consumed annually per Federal District inhabitant

\begin{tabular}{lcc}
\hline WTP & $\begin{array}{c}\mathrm{kg} \mathrm{year}^{-1} \text { per } \\
1000 \text { inhab. }^{\mathrm{a}}\end{array}$ & $\begin{array}{c}\text { Doses year } \\
1000 \text { inhab. }^{-1}\end{array}$ \\
\hline Melchior & 0.309 & 3095 \\
Asa-Sul & 0.291 & 2908 \\
Samambaia & 1.360 & 13603 \\
Asa-Norte & 0.611 & 6112 \\
Paranoá & 0.498 & 4980 \\
Riacho-Fundo & 0.209 & 2089 \\
\hline Extrapolated to $100 \%$ of & 0.394 & 3941 \\
FD population & \\
\hline
\end{tabular}

${ }^{a}$ Free base cocaine; btotal FD population: 2,580,757. 
Table 6. National cocaine use estimated via sewage epidemiology and comparison with reported official prevalence data

\begin{tabular}{|c|c|c|c|c|c|c|}
\hline Country & $\begin{array}{l}\text { Sampled } \\
\text { population }\end{array}$ & $\begin{array}{c}\text { Total } \\
\text { population }\end{array}$ & $\begin{array}{l}\text { Calculated cocaine } \\
\text { use / (tons year-1) }\end{array}$ & $\begin{array}{l}\mathrm{g} \mathrm{year}^{-1} \text { per } \\
\text { inhabitant }\end{array}$ & $\begin{array}{c}\text { Yearly } \\
\text { prevalence / }(\%)^{\mathrm{a}}\end{array}$ & Reference \\
\hline Belgium & 3.7 million & 10.5 million & 1.88 & 0.17 & 0.9 & 14 \\
\hline Spain & 1.4 million & 46.6 million & 21 & 0.46 & 3.1 & 13 \\
\hline United Kingdom & 141000 & 60.6 million & 19 & 0.31 & 2.3 & 16 \\
\hline Brazil & 1.6 million & 190.7 million & 75 & 0.39 & 0.7 & This work \\
\hline
\end{tabular}

${ }^{\text {aFrom EMCDDA }}{ }^{9}$ and UNODC. ${ }^{1}$

purity of $70 \%$ cocaine in seizures by the Federal Police in Brazil. Since in the Brazilian law enforcement system, the Federal Police is mainly responsible for investigations that results in seizures coming from international or interstate traffic, one can estimate that the effective trafficking of cocaine in the Federal District should be on the order of 1.5 tons per year.

The annual cocaine seizures conducted by Federal Police in the FD,,$^{23}$ are around $450 \mathrm{~kg}$. Thus they represent approximately $30 \%$ of the total consumed. Seizures of street samples, which are conducted by Brazilian state or military police, are not considered, since no chemical profile data are available to establish a common basis for comparison.

Some papers in the literature use extrapolation of regional consumption values for the entire population of the country (Table 6). In our case, this exercise of linear extrapolation led to a total of 75 tons for Brazil, expressed as free base cocaine. But this value has to be looked upon with special care, considering that Brazil is a continentalsized country and the present study was conducted in a relatively small metropolitan area. More comprehensive and routine studies should be performed to obtain more accurate estimates of national cocaine consumption.

The importance of the data obtained using sewage epidemiology in forensic, law enforcement, health and public education initiatives led the authors of this paper to propose a broader project to determine the quantities of cocaine, key metabolites and other illicit drugs in the Federal District, also addressing issues of seasonality, including all WTP and collaborating with a discussion about the increasing tendency observed for the use of smoked crack cocaine. The project called Quantification of Toxic Analytes (QuAnTox) has already received funding from Brazilian government agencies to encourage the research and to implement an appropriate structure for sample treatment and extraction to be carried out at the University of Brasilia.

The Brazilian government investment in projects like QuAnTox also finds justification in the global drug situation. In contrast to North America, where significant reduction in the use of cocaine and crack among the population has been observed, national experts in South America continue to report an increasing trend. ${ }^{1}$

Further studies should also be conducted focusing on the concentration ratio $\mathrm{BE} / \mathrm{COC}$ as an indicator of the occurrence of clandestine laboratories for preparation of crack cocaine, refining, or addition of cutting agents. It is possible to project the use of portable samplers for monitoring the sewage network as a searching tool for more precise location of areas of high consumption or significant production of drugs of abuse.

As mentioned above, the initial results of chemical profiling program (PeQui) shows that more than $70 \%$ of the cocaine seized in Brazil by Federal Police is constituted of free base cocaine (crude or refined), mainly consumed from smoking. Scientific investigations should also discuss the possibility of using specific metabolites, like the anhydroecgonine (ecgonidine), produced during the use of smoked cocaine (crack or pasta-base) ${ }^{24-27}$ to estimate the rate between the free base and the cocaine hydrochloride consumed.

\section{Conclusions}

The present work reports the quantification of cocaine and benzoylecgonine in the Brazilian Federal District (FD), via sewage analysis sampled at different wastewater treatment plants. The data obtained provides valuable, inexpensive and cost-effective information to be added to the classical socio-epidemiological studies, thus providing a more reliable estimate of cocaine consumption in this area.

Social interest of how this kind of research reaches lay people, has been confirmed by the immense attention dispensed by the local, national and international media to the data obtained in this pioneer work carried out in Brazil.

From the total estimated consumption of 1.0 ton of free base cocaine in FD, the sampling strategy used in this research provided an additional means of detecting areas with higher consumption in the region covered by the sewage network.

Collaborative work involving a team of environmental and analytical chemists guided by a forensic approach 
broadens the possibility of this type of work, as well as allowing a more comprehensive discussion, not only about illicit drugs but also about other emerging contaminants that are present in the sewage and may reach the drinking water system.

Unfortunately, in most developing countries, the lack of sanitation is a problem that seriously impairs this type of work, as sewer collection and treatment are, in most cases, inexistent or cover only a small portion of the metropolitan area.

Future works should be done in terms to optimize some parameters such as sampling requirements and strategies, degradation patterns of both parental and sub-products as well as the influence of the means of drug assimilation (smoked, inhaled, injected) in the metabolic profile.

\section{Supplementary Information}

The map of regions of the FD served by the six WTP studied is provided as supplementary information and available free of charge at http://jbcs.sbq.org.br as PDF file.

\section{Acknowledgments}

This work has been supported by the following projects: INCTAA/CNPq, FAPESP, FINEP/MCT (01.09.0275-00) and BRA I90/UNODC/PF. We also thank Dr. Carol Collins for revising the manuscript.

\section{References}

1. United Nations Office on Drugs and Crime (UNODC), World Drug Report 2010, United Nations: New York, 2010.

2. Presidency of the Republic; Establish the Comprehensive Plan to Combat Crack and other Drugs, Creates its Manager Committee, and other Matters, Decree n. 7,179, Brasília, Brazil, 2010.

3. Zacca, J. J.; Maldaner, A. O.; Besacier, F.; $20^{\text {th }}$ ANZFSS Symposium, Sydney, Australia, 2010.

4. Ehleringer, J. R.; Casale, J. F.; Lott, M. J.; Ford, V. L.; Nature 2000, 408, 311.

5. United Nations Office on Drugs and Crime (UNODC); Drug Characterization/Impurity Profiling - Background and Concepts, United Nations: New York, 2001.

6. United Nations Office on Drugs and Crime (UNODC); Methods for Impurity Profiling of Heroin and Cocaine, United Nations: New York, 2005.

7. Galduróz, J. C. F.; Noto, A. R.; Nappo, S. A.; Carlini, E. A.; Rev. Latino-Am. Enfermagem 2005, 13, 888.

8. Carlini, E. A.; II Household Survey on the use of Psychotropic Drugs in Brazil: Study Involving the 108 Largest Cities - 2005, CEBRID/UNIFESP: São Paulo, SP, Brasil, 2006.
9. European Monitoring Centre for Drugs and Drug Addiction (EMCDDA); Annual Report: The State of the Drugs Problem in Europe, Lisbon, 2009.

10. Zuccato, E.; Chiabrando, C.; Castiglioni, S.; Calamari, D.; Bagnati, R.; Schiarea, S.; Fanelli, R.; Environ. Health 2005, 4, 14.

11. Bones, J.; Thomas, K. V.; Paull B.; J. Environ. Monit. 2007, 9, 701.

12. Huerta-Fontela, M.; Galceran, M. T.; Ventura, F.; Anal. Chem. 2007, 79, 3821.

13. Postigo, C.; López de Alda, M. J.; Barceló, D.; Environ. Int. 2010, 36, 75.

14. van Nuijs, A. L. N.; Pecceu, B.; Theunis, L.; Dubois, N.; Charlier, C.; Jorens, P. G.; Bervoets, L.; Blust, R.; Meulemans, H.; Neels, H.; Covaci, A.; Addiction 2009, 104, 734.

15. Bartelt-Hunt, S. L.; Snow, D. D.; Damon, T.; Shockley, J.; Hoagland, K.; Environ. Pollut. 2009, 157, 786.

16. Kasprzyk-Hordern, B.; Dinsdale, R. M.; Guwy, A. J.; Environ. Pollut. 2009, 157, 1773.

17. Karolak, S.; Nefau, T.; Bailly, E.; Solgadi, A.; Levi, Y.; Forensic Sci. Int. 2010, 200, 153.

18. van Nuijs, A. L. N.; Castiglioni, S.; Tarcomnicu, I.; Postigo, C.; Alda, M. L.; Neels, H.; Zuccato, E.; Barceló, D.; Covaci, A; Sci. Total Environ. 2011, 409, 3564.

19. Ort, C.; Lawrence, M. G.; Rieckermann, J.; Joss, A.; Environ. Sci. Technol. 2010, 44, 6024.

20. State Department of Health, Federal District (SEDUH/ GDF); Projected Population by Age Groups in 2006 /2020, http://www.saude.df.gov.br accessed in November 2011.

21. Brazilian Institute of Geography and Statistics (IBGE); Population Census (2010/11/04), Official Gazette: Brasília, DF, Brasil, 2010.

22. Sodré, F. F.; Locatelli, M. A. F.; Jardim, W. F.; Quim. Nova 2010, 33, 216.

23. Regional Superintendence of the Federal Police Department in the Federal District (SR/DF/DPF); Management Report 2007, http://portal.mj.gov.br accessed in November 2011.

24. Costa, J. L.; Tonin, F. G.; Zanolli, L. A.; Chasin, A. A. M.; Tavares, M. F. M.; Electrophoresis 2009, 30, 2238.

25. Paul, B. D.; McWhorter, L. K.; Smith, M. L.; J. Mass Spectrom. 1999, 34, 651.

26. Paul, B. D.; Lalani, S.; Bosy, T.; Jacobs, A. J.; Huestis, M. A.; Biomed. Chromatogr. 2005, 19, 677.

27. Carvalho, V. M.; Chasin, A. A. M.; Carvalho, D. G.; Rev. Psiq. Clin. 2008, 35, 17.

Submitted: August 8, 2011 Published online: April 10, 2012

FAPESP has sponsored the publication of this article. 